\title{
Economic Sustainability Assessment of Groundwater Resources: Case Study of Hanoi, Vietnam
}

Nuong Thi Bui ${ }^{1}$, Akira Kawamura ${ }^{1}$, Hideo Amaguchi ${ }^{1}$, Duong Du Bui ${ }^{2}$, Ngoc Tu Truong ${ }^{3}$ and Hoang Nam Nguyen $^{4}$

1. Department of Civil and Environmental Engineering, Tokyo Metropolitan University, Tokyo 192-0397, Japan

2. Water Resources Monitoring Department, National Center for Water Resources Planning and Investigation, Hanoi 100000, Vietnam

3. The State Key Laboratory of Bioreactor Engineering, East China University of Science \& Technology, Shanghai 200237, China

4. Faculty of Urban and Environmental Natural Resource Economics \& Management, National Economics University, Hanoi, Vietnam

\begin{abstract}
The most useful indicators should be established, designed and customized based on local issues of a target area. In order to establish groundwater sustainability indicators for the Vietnam capital, Hanoi, in this study, the sustainability assessment framework of groundwater resources from an economic perspective is proposed for the first time with the focus of Hanoi current groundwater problems. An AHP (Analytical Hierarchy Process) approach is employed to generate the main components (aspects and indicators) of this framework, because development of composite indicators is considered to be a best approach for sustainability evaluation. To do this, the current problems of Hanoi groundwater resources were carefully reviewed and explored to propose three main aspects (quantity, quality and management) and appropriately construct their 9 MESIs (Macroeconomic Sustainability Indicators). As for the results, the sustainability indices of the quantity, quality and management aspects were appropriately assessed as good, excellent and good sustainability levels, respectively. As a result, the sustainability of Hanoi groundwater resources development is economically good, indicating that there has been a big effort to improve the groundwater sustainability from both sides, the local government and communities.
\end{abstract}

Key words: Groundwater, MESI, sustainability assessment, AHP, Hanoi.

\section{Introduction}

"Act locally", but need to "think globally". This concept has been critically emphasized for any economic sector to ensuring sustainable development of communities, cities and countries. Water resources development is nowadays getting more attention from both researchers and practitioners worldwide because ensuring safe and affordable drinking water for all is one of the universal targets of the 17 United Nations Sustainable Development Goals [1].

In Hanoi, Vietnam, groundwater resources is the most important water supply sources (accounting 93\% of domestic water use contribution [2]), for the

Corresponding author: Nuong Thi Bui, Ph.D. candidate, main research fields: sustainable natural resources development and environmental sciences. communities here where most of the rivers and lakes here are seriously polluted due to the discharge of untreated industrial, agricultural, aquacultural and domestic waste [3]. The resource also significantly contributes to Hanoi industrial and service sectors with a high proportion of $77 \%$ [4]. Unfortunately, this groundwater recently become seriously degraded in both quantity and quality perspectives due to the rapid exploitation of the groundwater without an appropriate management. From a quantity point of view, the aquifer system and groundwater potential resources for Hanoi was explored [5] and the whole RRD (Red River Delta) where Hanoi is located [6] but also evidently showed the seriously declining groundwater levels in Hanoi central areas [7]. From a quality point of view, the hydrogeochemical characteristics of groundwater in Hanoi and the RRD were investigated [8, 9], 
crucially supporting the hydrogeochemical assessment of groundwater quality during dry and rainy seasons for this target area [10] and the whole RRD [11]. As for the results of a series of Hanoi groundwater quality assessment studies, the groundwater resource has been locally contaminated mainly by arsenic, coliform and nitrogen [12-14]. These serious quantity and quality degradations require a certain budget for groundwater abstraction, appropriate treatment and long-term remediation, thus threatening the community's goal of sustainable groundwater development.

Therefore, it is necessary to measure sustainability of Hanoi groundwater resources. As one of the developing countries, economic benefits and development in Vietnam are always put at higher priorities compared to two other sustainable development goals (social and environment) [15]. This research thus is first trial to assess sustainability of Hanoi groundwater resources from an economic perspective. In order to measure sustainability, the concept of sustainability assessment was defined as “...a tool that can help decision-makers and policy-makers decide which actions they should or should not take in an attempt to make society more sustainable" [16]. Development of composite indicators is considered to be a unique approach for sustainability evaluation and sustainability indices are very useful in focusing attention and, often simplify the problem [17]. Regarding sustainability assessment methodologies, MCDM (Multi-Criteria Decision Making) is considered to be the best approach [18], and AHP (Analytical Hierarchy Process), an outstanding MCDM, is usually used for various sustainability assessment projects including the mining sector [19, 20], environmentally sustainable evaluation [21] and regional water resources [22]. The main advantage of those AHP applications is that they can categorize and identify the foremost components (aspects and indicators) that better reflect the significant performance. The indicator-based AHP approach is thus acknowledged as the most commonly used tool for sustainability assessment. However, there have been no studies dealing with the indicator-based AHP approach for groundwater sustainability assessment previously. It is, therefore, necessary to develop a MESI (Macroeconomic Sustainability Indicator) set for groundwater based on the feasible AHP approach.

Dealing with the above mentioned problems, this study aims to utilize the AHP concept to define an appropriate MESI set for the establishment of a groundwater sustainability assessment framework with focus of an economic perspective. By carefully reviewing and exploring the current problems of Hanoi groundwater resources, this study assesses economic sustainability of the resource and describes how the economic sustainability indices could reflect the actual situation of groundwater problems in Hanoi. The conventional AHP approach is modified to cope with the limited data availability in the target area. Finally, ideas on how to improve the sustainability assessment were discussed and suggested.

\section{Study Area}

The geographical location and the main rivers and lakes of Hanoi are displayed in Fig. 1. Hanoi is located in the northeastern part of Vietnam covering an area of $3,324.5 \mathrm{~km}^{2}$. Its population of more than 7.2 million (2015) accounts for almost $10 \%$ of Vietnam's total population, with a population density of more than 2,000 people $/ \mathrm{km}^{2}$ [23], is the highest in Vietnam. Hanoi belongs to the tropical monsoonal area with two distinctive annual seasons, the rainy and dry seasons. The annual average rainfall is about $1,600 \mathrm{~mm}$; the average humidity is about $80 \%$; and the average temperature is about $24.3^{\circ} \mathrm{C}$. Evaporation is quite high with an annual average of $933 \mathrm{~mm}$ [5]. Hanoi also has a dense river network $\left(0.7 \mathrm{~km} / \mathrm{km}^{2}\right)$ and is a part of the Red River of which the basin area is approximately $155,000 \mathrm{~km}^{2}$. However, rapid urbanization has put great pressure on the river basin environment, and the surface water is seriously polluted [5]. Thus, 


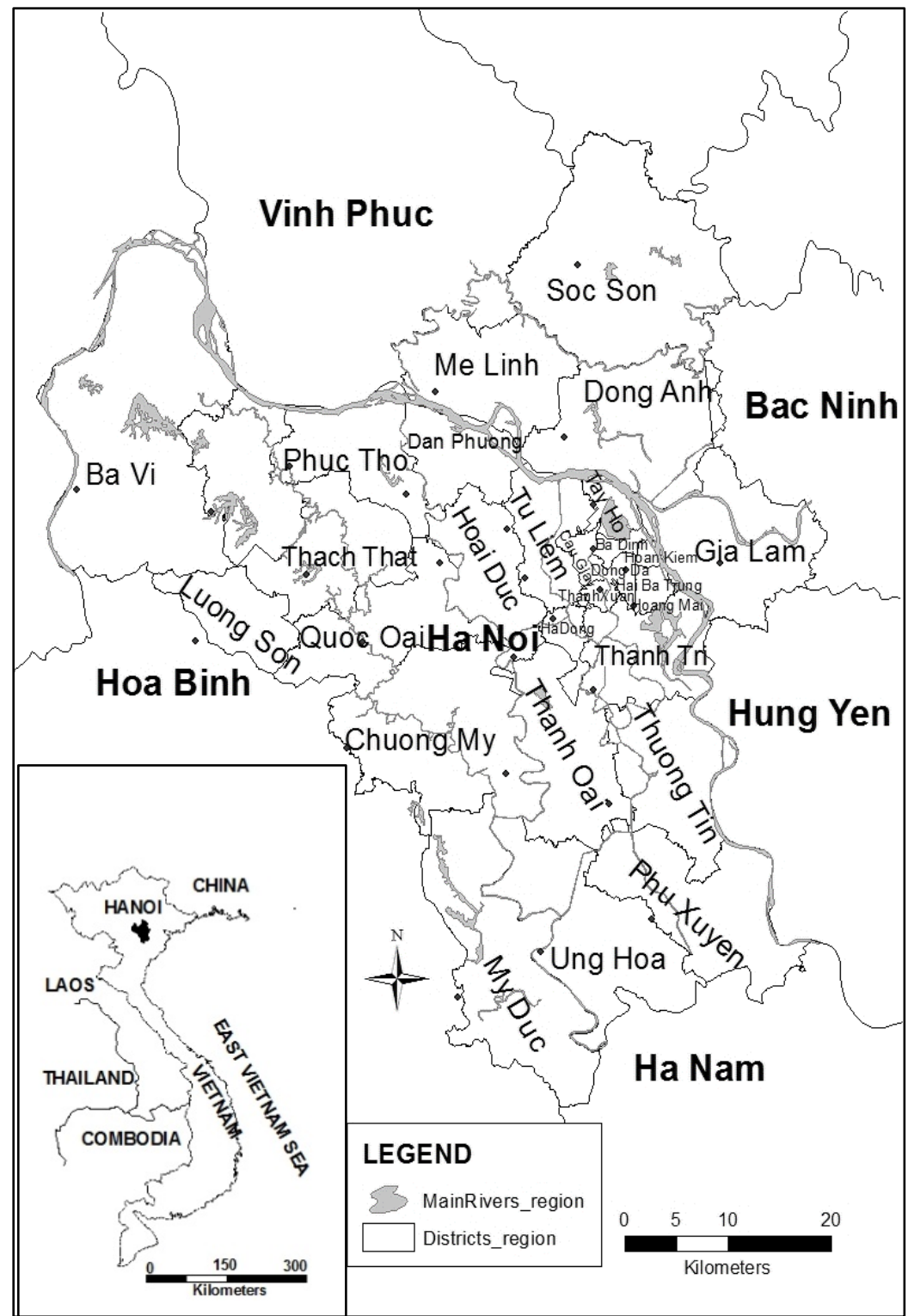

Fig. 1 Study area, main rivers and lakes.

groundwater becomes the most important water source, which is accounting for $93 \%$ of domestic water use contribution for the communities [2]. Currently, up to $632,172 \mathrm{~m}^{3} /$ day of groundwater is exploited for water supply purpose [4]. Hanoi government now is trying to reduce this pressure on groundwater abstraction by establishing several surface water treatment plants to use the water resources from rivers in Hanoi and nearby.

Hanoi groundwater not only contribute to domestic water use but also contribute to industrial and service. According to MONRE (Ministry of Natural Resources and Environment) [4], approximately 693,572.7 $\mathrm{m}^{3} /$ day of groundwater is abstracted for industrial and service purposes; expecting that the industrial water demand will be about $82,000 \mathrm{~m}^{3} /$ day in 2020 (No.499/QD-TTg, March 21, 2013). According to HAWACO (Hanoi Water Limited Company) [2], the largest water distribution company in Hanoi, $55 \%$ of the city's population, or 3.6 million users, have access to public water system, which is a quality-controlled source; the urban and suburban districts have $100 \%$ and $42 \%$ public water coverage, respectively. Although 
public water fully covers all the urban districts, about $30 \%$ of households still used freely accessed water from their private and community wells in 2010 without any quality standard [24]. The reason for this unreliable water use manner is due to not only the unstable water supply quantity but also their low monthly incomes compared to the monthly water bills [25].

\section{Methodology}

Established in the 1970s by Saaty, T. L. [26], AHP is one of the most powerful and popular MCDM methods dealing with multifaceted and unstructured problems such as political, economic, social and management sciences. So far, the AHP approach has been usually and effectively used for sustainability assessment of various application fields $[19,20,21,27]$. The four basic steps of AHP application and its modification in this study are present as:

Step 1: Build up a Sustainability Hierarchy:

The first step in an AHP application is to create a hierarchy by breaking the targeted MCDM problems of sustainability (in this case, economic sustainability) down into its aspects (SA) and indicators (SI). In this step, the basic knowledge of the current situations, actual problems and expected goal should be carefully considered [28]. The Sis should be the smallest component in the hierarchy and physically measurable. Defining Sas and Sis is among the most challenging tasks in AHP sustainability application.

Step 2: Weighting Process:

Generally, the weights refer to the relative contributions of the components (aspects and indicators) to the final goal of sustainability. The conventional way of determining these relative contributions is very tedious due to the need to (i) find the appropriate experts, (ii) wait for their big efforts to make the large series of pair-wise comparison judgments, especially in case of a large indicator set, and even (iii) ask the experts to repeatedly make the judgments until acceptably consistent judgments are obtained. In developing countries like Vietnam, however, carrying out such complicated surveys regarding groundwater sustainability seems to be difficult without enough financial support. Therefore, in the previous study [29], the conventional AHP was modified to make it simple by flexibly weighting the contribution of each SA and SI to the final goal. In this simple AHP approach, weights are derived as a function of the number of aspects and indicators. For the simplest weighting case, particularly in this study, the aspect and indicator weights are equally evaluated as the first trial by using the Eqs. (1) and (2):

$$
\begin{gathered}
W_{A}(i)=\frac{1}{N} \\
W_{I}(i, j)=\frac{1}{N_{i}}
\end{gathered}
$$

with the constraints:

$$
\begin{gathered}
0 \leq W_{A}(i), W_{I}(i, j) \leq 1 \\
\sum_{i=1}^{N} W_{A}(i)=1 ; \sum_{j=1}^{N_{i}} W_{I}(i, j)=1
\end{gathered}
$$

Where $W_{A}(i)$ : the weight of the $i^{\text {th }}$ aspect; and $W_{I}(i, j)$ : the weight of the $j^{\text {th }}$ indicator in the $i^{\text {th }}$ aspect. $N$ : number of the aspects; $N_{i}$ : number of the indicators in the $i^{\text {th }}$ aspect; $i=1 \ldots N ; j=1 \ldots N_{i}$;

Step 3: Data Collection:

The third step is to collect the data for indicator value evaluations. The raw indicator values vary; thus, in this step, a transformation method is usually needed to make the indicator values dimensionless and in the range of 0 to 1 . The transformed indicator values then automatically have been considered as their sustainability indices for those raw indicators. In this study, there is an effort to define the MESIs with their appropriate index-based definitions, the values of MESIs conceptually are in the range of 0 to 1 . So that there is no need any transformation method as it is usually needed in the AHP sustainability assessment literature.

Step 4: Sustainability Assessment:

The fourth step is to assess sustainability performance. Simply put, the final sustainability index 
Table 1 Sustainability scale.

\begin{tabular}{lll}
\hline No. & Sustainability level & Sustainability index \\
\hline 1 & Very poor & $0<\Omega_{I}, \Omega_{A}, \Omega \leq 0.2$ \\
2 & Poor & $0.2<\Omega_{I}, \Omega_{A}, \Omega \leq 0.4$ \\
3 & Acceptable & $0.4<\Omega_{I}, \Omega_{A}, \Omega \leq 0.6$ \\
4 & Good & $0.6<\Omega_{I}, \Omega_{A}, \Omega \leq 0.8$ \\
5 & Excellent & $0.8<\Omega_{I}, \Omega_{A}, \Omega \leq 1.0$ \\
\hline
\end{tabular}

is obtained from the indicator values and their derived weights. The sustainability index $\Omega_{I}(i, j)$ of the $j^{\text {th }}$ indicator in the $i^{\text {th }}$ aspect is evaluated based on the specific considerations for the aspects, indicators and the sustainability goal. Once all the components of the sustainability hierarchy and SIF for indicators are determined, $\Omega_{I}(i, j)$ can be simply calculated according to the actual data. The sustainability index $\Omega_{A}(i)$ for the $i^{\text {th }}$ aspect and the final sustainability index $\Omega$ are evaluated by using Eqs. (5) and (6), respectively:

$$
\begin{aligned}
\Omega_{A}(i) & =\sum_{j=1}^{N_{i}} W_{I}(i, j) * \Omega_{I}(i, j) \\
\Omega & =\sum_{i=1}^{N} W_{A}(i) * \Omega_{A}(i)
\end{aligned}
$$

Naturally, sustainability indices $\Omega_{I}, \Omega_{A}$ and $\Omega$ are in the range of 0 to 1 and usually categorized into several classes known as sustainability scales. This study adopts the sustainability scale of Bui, T. N., et al. [29], which is shown in Table 1.

\section{Economic Sustainability Assessment Framework for Hanoi Groundwater Resources}

Referred to indicator establishment from the UNESCO/IAEA/IAH Working Group, this study is an attempt to design and customize the most useful indicators based on local groundwater issues in Hanoi.

\subsection{Quantity Aspect and Its Index-based MESIs}

As mentioned in the Study Area Section, Hanoi groundwater not only contribute to domestic water use but also contribute to industrial and service. It is apparently important to consider how much groundwater contributes to these economic sectors of Hanoi economic development from quantity aspect. So that for quantity aspect $\left(\mathrm{SA}_{1}\right)$, the indicator $\mathrm{SI}_{11}$ shows the proportion of groundwater contributed to domestic water use purpose; $\mathrm{SI}_{12}$ demonstrates the proportion of groundwater contributed to industrial and service purposes. For the third indicator, $\mathrm{SI}_{13}$ is a measure of how much water supply which is efficient for use. The reason is that even the excessive groundwater abstraction has caused serious groundwater-level declines, the public water utilities failed to supply urban districts approximately every two days per month [30]. The water loss is reported at the high rate of $38 \%$ in Hanoi due to the inappropriate pipe system [31]. By these index-based definitions, the MESI values are in the range of zero to one. Those indicators of the first aspect $\left(\mathrm{SA}_{1}\right)$ and their index-based definitions are shown in Table 2.

\subsection{Quality Aspect and Its Index-based MESIs}

From a quality point of view, as mentioned in Hanoi groundwater situation literature review, the resource is seriously polluted. Thus it is important to consider how much monetary need is looked-for groundwater remediation $\left(\mathrm{SI}_{21}\right)$, because groundwater contamination is extremely expensive to remediate. $\mathrm{SI}_{21}$ in this case is defined as one minus the ratio of the remediation cost for groundwater contamination to Hanoi GDP on average to make the positive relation between indicator value and its sustainability index. For the second indicator of quality aspect, according to Economics of Sanitation Initiative of Water and Sanitation Program of World Bank [32], 260 million USD is estimated for Vietnam economic loss because the communities' health problems are closely related to the low-quality water use. So here how much the communities need to pay for their water-related disease treatment $\left(\mathrm{SI}_{22}\right)$ is considered. $\mathrm{SI}_{22}$ is also defined as one minus the ratio of the estimated loss from water-related diseases to Hanoi GDP in a target year. These indicators are important in terms of groundwater quality because the demand for 
clean and safe water has become urgent not only in Vietnam but also in all developing countries [33].

\subsection{Management Aspect and Its Index-based MESIs}

Water resources development is derived and controlled by two main management powers, the local government and communities. Regarding government side, this study here considers how local government manages and improves the public water supply as the stable quantity and controlled quality sources for the community. Based on the current eco-social situation, the first indicator $\left(\mathrm{SI}_{31}\right)$ refers to public water coverage. This indicator reflects how much the distribution network can reach the community. The second indicator $\left(\mathrm{SI}_{32}\right)$ in this aspect is related to the annual investment per capita compared to the required unit cost for water supply facilities. This indicator shows how much the government cares about water resources development sector in terms of budget allocation. Regarding the community side, it is also necessary to consider how the community responds to the management and water-related policies, and how ready the community is for better water supply. So that the indicator $\mathrm{SI}_{33}$ is a measure of how the current water is affordable or cheap enough compared to the average household income of the communities. Because the maximum water prices is somehow reaching $28 \%$ of the average income of Hanoi's population, considering 104.00 USD per month [24]. This water price-income relation apparently causes pretty much difficulty for the households whether they want to use the better quality water sources. For the last indicator in the community side, the $\mathrm{SI}_{34}$ is defined as the ratio of residents' willingness to pay for improving the water supply system to their current water bills. $\mathrm{SI}_{34}$ thus shows not only the degree of public awareness but also how ready the communities are for a better quality water use (Table 2).

Finally, three main sustainability aspects (quantity, quality and management) and their respectively three, two and four corresponding MESIs are proposed and defined to build up the economic sustainability hierarchy for Hanoi groundwater mainly based on the current problem consideration (Table 2).

After the weights for the aspects and indicators are obtained from Eqs. (1) and (2), the sustainability indices for $\Omega_{A}$ and the final economic sustainability index $\Omega$ are calculated by Eqs. (5) and (6), respectively. Those resulting sustainability indices are shown in Table 3 and their visualization is shown in Fig. 2.

Table 2 Economic sustainability assessment framework for groundwater in Hanoi.

\begin{tabular}{|c|c|c|c|c|}
\hline Aspect & Indicator & Consideration & Index-based definition & Benefit/Cost \\
\hline \multirow{3}{*}{$\begin{array}{l}\text { Quantity } \\
\left(\mathrm{SA}_{1}\right)\end{array}$} & $\mathrm{SI}_{11}$ & $\begin{array}{l}\text { Domestic water use } \\
\text { contribution }\end{array}$ & $\begin{array}{l}\text { Groundwater as a percentage of the Hanoi total water use for } \\
\text { domestic purpose }\end{array}$ & Benefit \\
\hline & $\mathrm{SI}_{12}$ & $\begin{array}{l}\text { Industrial and service } \\
\text { water use contribution }\end{array}$ & $\begin{array}{l}\text { Groundwater as a percentage of the Hanoi total water use for } \\
\text { industrial purpose }\end{array}$ & Benefit \\
\hline & $\mathrm{SI}_{13}$ & Effective water supply & Effective water supply as a percentage of the total water supply & Benefit \\
\hline \multirow{2}{*}{$\begin{array}{l}\text { Quality } \\
\left(\mathrm{SA}_{2}\right)\end{array}$} & $\mathrm{SI}_{21}$ & $\begin{array}{l}\text { Groundwater } \\
\text { remediation cost }\end{array}$ & $\begin{array}{l}\text { One minus the ratio of the remediation cost for GW contamination } \\
\text { to Hanoi GDP on average }\end{array}$ & Cost \\
\hline & $\mathrm{SI}_{22}$ & $\begin{array}{l}\text { Water-related disease } \\
\text { cost }\end{array}$ & $\begin{array}{l}\text { One minus the ratio of the estimated loss from water-related } \\
\text { diseases to Hanoi GDP on average }\end{array}$ & Cost \\
\hline \multirow{4}{*}{$\begin{array}{l}\text { Management } \\
\left(\mathrm{SA}_{3}\right)\end{array}$} & $\mathrm{SI}_{31}$ & Public water coverage & Ratio of the coverage from the public water distribution network & Benefit \\
\hline & $\mathrm{SI}_{32}$ & Investment & $\begin{array}{l}\text { Ratio of the annual investment in water supply per capita to the } \\
\text { estimated unit costs for water supply facilities }\end{array}$ & Benefit \\
\hline & $\mathrm{SI}_{33}$ & Affordable water & $\begin{array}{l}\text { One minus the ratio of the average water prices to the average } \\
\text { capital income }\end{array}$ & Benefit \\
\hline & $\mathrm{SI}_{34}$ & Willing payability & $\begin{array}{l}\text { Ratio of the average household willingness to pay for improving } \\
\text { the water supply system to their average water bill per month }\end{array}$ & Benefit \\
\hline
\end{tabular}


Table 3 Economic sustainability assessment for Hanoi groundwater resources.

\begin{tabular}{|c|c|c|c|c|c|c|c|}
\hline \multirow{2}{*}{ Aspect } & \multirow{2}{*}{$W_{A}$} & \multirow{2}{*}{ Indicator } & \multirow{2}{*}{$W_{I}$} & \multirow{2}{*}{ Indicator value } & \multicolumn{3}{|c|}{ Economic sustainability assessment } \\
\hline & & & & & $\Omega_{I}$ & $\Omega_{A}$ & $\Omega$ \\
\hline \multirow{3}{*}{$\begin{array}{l}\text { Quantity } \\
\left(\mathrm{SA}_{1}\right)\end{array}$} & \multirow{3}{*}{0.333} & $\mathrm{SI}_{11}$ & 0.333 & 0.930 & 0.930 & \multirow{3}{*}{$\begin{array}{l}0.773 \\
\text { (Good) }\end{array}$} & \multirow{9}{*}{$\begin{array}{l}0.783 \\
\text { (Good) }\end{array}$} \\
\hline & & $\mathrm{SI}_{12}$ & 0.333 & 0.770 & 0.770 & & \\
\hline & & $\mathrm{SI}_{13}$ & 0.333 & 0.620 & 0.620 & & \\
\hline \multirow{3}{*}{$\begin{array}{l}\text { Quality } \\
\left(\mathrm{SA}_{2}\right)\end{array}$} & \multirow{3}{*}{0.333} & $\mathrm{SI}_{21}$ & 0.500 & 0.740 & 0.740 & \multirow{3}{*}{$\begin{array}{l}0.869 \\
\text { (Excellent) }\end{array}$} & \\
\hline & & $\mathrm{SI}_{22}$ & 0.500 & 0.998 & 0.998 & & \\
\hline & & $\mathrm{SI}_{31}$ & 0.250 & 0.680 & 0.680 & & \\
\hline \multirow{3}{*}{$\begin{array}{l}\text { Management } \\
\left(\mathrm{SA}_{3}\right)\end{array}$} & \multirow{3}{*}{0.333} & $\mathrm{SI}_{32}$ & 0.250 & 0.630 & 0.630 & \multirow{3}{*}{$\begin{array}{l}0.708 \\
\text { (Good) }\end{array}$} & \\
\hline & & $\mathrm{SI}_{33}$ & 0.250 & 0.850 & 0.850 & & \\
\hline & & $\mathrm{SI}_{34}$ & 0.250 & 0.670 & 0.670 & & \\
\hline
\end{tabular}

In terms of quantity aspect $\left(\mathrm{SA}_{1}\right)$, the indicator $\mathrm{SI}_{11}$ is assessed at the excellent sustainability level of 0.930 according to the sustainability scale shown in Table 1 , indicating that Hanoi domestic water supply almost completely depends on groundwater resources abstraction. The groundwater also significantly contributes to the water consumption of industrial and service activities with the good sustainability index of 0.770 . These evaluations reveal the vital role of groundwater resources in Hanoi economic development. The indicator $\mathrm{SI}_{13}$ is assessed at the good sustainability level of 0.62 , indicating that $38 \%$ of the water supply in effectively reaches the water users. The total capacity of all the water supply companies in HAWACO is $534,500 \mathrm{~m}^{3} /$ day [30], so that the economic loss due to this ineffective water supply is approximately estimated as 1.6 billion VND/day (about 70,000 USD/day at the current rate of $(1 \mathrm{USD}=$ $22,767 \mathrm{VND}$ ) and water price of $8,000 \mathrm{VND} / \mathrm{m}^{3}$ ). Consequently, the good sustainability level is economically assessed for the quantity aspect with the index $\Omega_{A}$ (1) of 0.773 (Table 3 and Fig. 2).

Similarly, in terms of quality, $\mathrm{SI}_{21}$ and $\mathrm{SI}_{22}$ indicators regarding groundwater remediation and water-related disease costs are assessed at the good and even excellent economic sustainability levels of 0.740 and 0.998 , respectively. These economic sustainability indices show that the economic losses due to the adverse impacts of contaminated groundwater to human health are negligible for a short term consideration (in this case, a year as the index-based definitions of $\mathrm{SI}_{21}$ and $\mathrm{SI}_{22}$ ). However, the groundwater is seriously polluted in the literature and it was estimated that 10 million people in the Red River Delta where Hanoi is located are affected due to arsenic exposure [12] for instance. Therefore, these economic sustainability assessments suggest that the MESIs of $\mathrm{SA}_{2}$ should be considered in a long term period to see clearly how significantly the economic loss will be due to the currently severe groundwater contamination in Hanoi. The quality aspect is economically assessed at the excellent level (Table 3 and Fig. 2).

In terms of management aspect $\left(\mathrm{SA}_{3}\right)$, all indicators are assessed at good and even excellent sustainability level. The indicator $\mathrm{SI}_{31}$ shows that the public water system covers about two-thirds of Hanoi communities. The investment indicator $\mathrm{SI}_{32}$ is assessed at good economic sustainability level, which reveals that Hanoi government recently gives much attention to increase their budget allocation for water supply improvement. In a number of households, more than one-tens (15\%) as the average monthly incomes are spent for water consumption based on the assessment of the indicator $\mathrm{SI}_{33}$. In comparison with the "water bill-average household income" percentages in Japan of $0.15 \%$, and in United Kingdom and Wales of $1.50 \%$ in 2016 [34, 35], it is quite difficult for a part of Hanoi communities to afford for their monthly water bills based on their own incomes. The last indicator, $\mathrm{SI}_{34}$ is economically assessed at good level of 0.670 indicating that $58 \%$ (as the results from the survey in 2017) of the communities are willing to pay more than half of their current water 


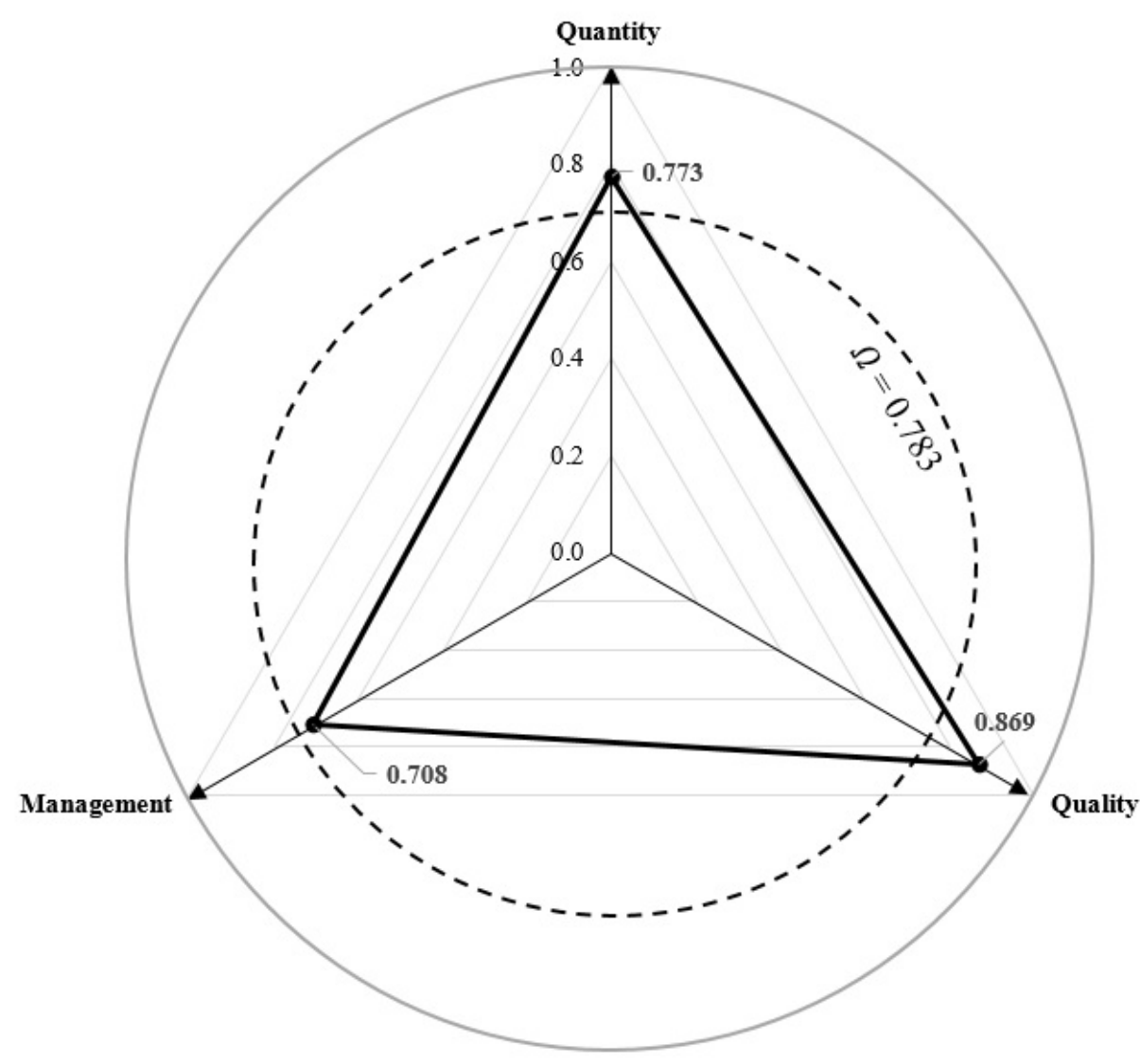

Fig. 2 Visualization of economic sustainability assessment for Hanoi groundwater resources.

bills for a better water use condition. This is a positive signal from the communities for implementation of water supply improvement projects. As a result, the economic sustainability index of the management aspect is assessed at the good level of 0.708 .

Consequently, the economic sustainability index $\Omega$ of Hanoi groundwater is assessed at a good sustainability level of 0.783 (Table 3). In Fig. 2, the economic sustainability indices for the three aspects are shown as a solid line triangle in the radar chart. The final economic sustainability index $\Omega$ is also shown as the solid line circle with the radius equal to $\Omega$ value.

\section{Conclusion}

This study carried out sustainability assessment of groundwater resources in Hanoi from an economic perspective. To do that, the most tedious weighting process in the conventional AHP approach was modified to cope with the limited data availability in Hanoi. The three main aspects (including quantity, quality and management) and their corresponding three, two and four MESIs, which appropriately represent the current economic situation of Hanoi groundwater, were practically proposed. In addition, the sustainability of groundwater in Hanoi is successfully assessed from an economic perspective.

As for the results, the quantity, quality and management aspects are economically assessed at good, excellent and good sustainability levels, respectively, resulting a good assessment for the final economic sustainability index. The results not only (i) confirm the vital role of the groundwater resource in Hanoi economic development; (ii) estimate the economic loss of 70,000 USD/day due to the ineffective water supply facilities in Hanoi; (iii) reveal the great efforts from both sides, local government and communities to 
improve water supply facilities; but also (iv) suggest that MESIs of the quality aspect should be considered in a long term period to show more accurately significant loss due to the currently serious situation of Hanoi groundwater problems. These findings could be useful for further sustainability assessment of groundwater resources in Hanoi.

\section{Acknowledgment}

This study was carried out as a part of the research project "Study on Guerrilla Rainstorms, Flood Inundation and Water Pollution in Metropolitan Watersheds" supported by the Tokyo Metropolitan Government, Japan (represented by Akira Kawamura). The authors would like to thank the MONRE (Ministry of Natural Resources and Environment) of Vietnam for supplying the necessary field data from the earlier feasibility studies.

\section{References}

[1] United Nations. 2017. "Sustainable Development Goals." Accessed $\quad$ November 2017. http://www.undp.org/content/undp/en/home/sustainable-d evelopment-goals.html.

[2] HAWACO (Hanoi Water Limited Company). 2014. "Hanoi Water Supply System." Presented at the 37th WEDC International Conference of Sustainable Water and Sanitation Services for All in a Fast Changing World, Co-hosted by Loughborough University and The National University of Civil Engineering.

[3] Tong, T. N. 2008. Establishing Integrated Water Resources Database for Effective Management in Hanoi. The final project report of Northern Division of Water Resources Planning and Investigation, In Vietnamese.

[4] MONRE (Ministry of Natural Resources and Environment). 2016. Groundwater Protection in Major Cities in Vietnam. National Center for Water Resources Planning and Investigation, Water Resources Monitoring Department.

[5] Bui, D. D., Kawamura, A., Tong. T. N., Amaguchi, H., and Trinh, T. M. 2012. "Aquifer System for Potential Groundwater Resources in Hanoi, Vietnam." Hydrological Processes 26 (6): 932-46.

[6] Bui, D. D., Kawamura, A., Tong. T. N., Amaguchi, H., Nakagawa, N., and Iseri, Y. 2011. "Identification of Aquifer System in the Whole Red River Delta, Vietnam." Geosciences Journal 15 (3): 323-38.
[7] Bui, D. D., Kawamura, A., Tong. T. N., Amaguchi, H., and Nakagawa, N. 2012. "Spatio-temporal Analysis of Recent Groundwater-level Trends in the Red River Delta, Vietnam." Hydrogeology Journal 20 (8): 1635-50.

[8] Nguyen, T. T., Kawamura, A., Tong, T. N., Nakagawa, N., Amaguchi, H., and Gilbuena, R. 2014. "Hydrogeochemical Characteristics of Groundwater from the Two Main Aquifers in the Red River Delta, Vietnam." Journal of Asian Earth Sciences 93: 180-92.

[9] Nguyen, T. T., Kawamura, A., Tong, T. N., Nakagawa, N., Amaguchi, H., Gilbuena, R, and Bui, D. D., 2015. "Identification of Spatio-seasonal Hydrogeochemical Haracteristics of the Unconfined Groundwater in the Red River Delta, Vietnam." Applied Geochemistry 63: 10-21.

[10] Nguyen, T. T., Kawamura, A., Tong, T. N., Nakagawa, N., Amaguchi, H., and Gilbuena, R. 2015. "Hydrogeochemical Assessment of Groundwater Quality during Dry and Rainy Seasons for the Two Main Aquifers in Hanoi, Vietnam." Environmental Earth Sciences 73: 4287-303.

[11] Nguyen, T. T., Kawamura, A., Tong, T. N., Nakagawa, N., Amaguchi, H., and Gilbuena, R. 2015. "Clustering Spatio-seasonal Hydrogeochemical Data Using Self-organizing Maps for Groundwater Quality Assessment in the Red River Delta, Vietnam." Journal of Hydrology 55: 661-73.

[12] Berg, M., Nguyen, T. C., Pham, H. V., Schertenleib, R., and Giger, W. 2001. "Arsenic Contamination of Groundwater and Drinking Water in Vietnam: A Human Health Threat." Environment Earth Sciences 35 (13): 2621-6.

[13] Berg, M., Pham, T. K. T, Stengel, C., Buschmann, J., Pham, H. V., Nguyen, V. D., et al. 2008. "Hydrological and Sedimentary Controls Leading to Arsenic Contamination of Groundwater in the Hanoi Area, Vietnam: The Impact of Iron-arsenic Ratios, Peat, River Bank Deposits, and Excessive Groundwater Abstraction." Chemical Geology 249 (1): 91-112.

[14] Bui, D. D., Bui, N. T., Hoang, H. A., Do, T. H., and Bui, D. D. 2007. "Research on the Groundwater Pollution and Its Effect on the Community Health in Hanoi, Vietnam with the Supports of GIS and Mathematical Model." In Proceedings of the International Workshop on Bio-Medicine, 338-45.

[15] Brundtland, G. H. 1987. Our Common Future. Oxford University Press.

[16] Devuyst, D., Hens, L., and Lannoy, W. D. 2001. How Green is the City? Sustainability Assessment and the Management of Urban Environments. New York: Columbia University Press.

[17] Atkinson, G. D., Dubourg, R., Hamilton, K., Munasignhe, M., Pearce, D. W., and Young, C. 1997. Measuring 
Sustainable Development: Macroeconomics and the Environment. Cheltenham, UK: Edward Elgar.

[18] Boggia, A., and Cortina, C. 2010. "Measuring Sustainable Development Using a Multi-criteria Model: A Case Study." Environmental Management 91: 2301-6.

[19] Bui, T. N., Kawamura, A., Kim, K. W., Prathumratana, L., Kim, T. H., Yoon, S. H., et al. 2017. "Proposal of an Indicator-based Sustainability Assessment Framework for The Mining Sector of APEC Economies." Resources Policy 52: 405-17.

[20] Singh, R. K., Murty, H. R., Gupta, S. K., and Dikshit, A. K. 2007. "Development of Composite Sustainability Performance Index for Steel Industry." Ecological Indicator 7 (3): 565-88.

[21] Si, H., Bi, H., Li, X., and Yang, C. 2010. "Environmental Evaluation for Sustainable Development of Coal Mining in Qijiang, Western China." International Journal of Coal Geology 81 (3): 163-8.

[22] Sun, S., Wang, Y., Liu, J., Cai, H., Wu, P., Geng, Q., et al. 2016. "Sustainability Assessment of Regional Water Resources under the DPSIR Framework." Journal of Hydrology 532: 140-8.

[23] General Statistic Office of Vietnam. 2015. "Area, Population and Population Density by Province by Cities, Provinces." Accessed November 20, 2015. http://www.gso.gov.vn/default_en.aspx?tabid=774.

[24] UNDP. 2010. "Urban Poverty Assessment in Hanoi and Ho Chi Minh City." Accessed September 14, 2017. http://www.vn.undp.org/content/vietnam/en/home/library /poverty/urban-poverty-assessment-in-ha-noi-and-ho-chiminh-city.html.

[25] Lucía, W. C., March, H., and Schramm, S. 2017. "Fragmented Landscapes of Water Supply in Suburban Hanoi." Habitat International 61: 64-74.

[26] Saaty, T. L. 2000. Fundamentals of Decision Making and Priority Theory. Pittsburgh, PA: RWS Publications.

[27] Yaylac1, D. E., and Düzgün, H. S. 2016. "Indicator-based
Sustainability Assessment for the Mining Sector Plans: Case of Afşin-Elbistan Coal Basin." International Journal of Coal Geology 165: 190-200.

[28] Randolph, B., and Troy, P. 2008. "Attitudes to Conservation and Water Consumption." Environmental Science \& Policy 11 (5): 441-55.

[29] Bui, T. N., Kawamura, A., Amaguchi, H., Bui, D. D., and Truong, N. T. 2016. "Environmental Sustainability Assessment of Groundwater Resources in Hanoi, Vietnam by a Simple AHP Approach." Journal of Japan Society of Civil Engineers, Ser. G (Global Environmental Research) 72 (5): I137-46.

[30] HAWACO. 2016. "Temporary Water Shut-off Schedule." Accessed October 20, 2016. http://hawacom.vn/?cat=67.

[31] ADB. 2010. Strategic Assessment for Water Supply and Sanitation (in Vietnamese). Vietnam country report.

[32] World Bank. 2012. Economics of Sanitation Initiative of Water and Sanitation Program. World Bank.

[33] JICA (Japan International Cooperation Agency). 2016. "Safe Water for All." Accessed July 26, 2017. https://www.jica.go.jp/english/publications/brochures/c8h 0vm0000avs7w2-att/japan_brand_05.pdf.

[34] City-Cost. 2017. "Utilities in Japan: Monthly Spending on Electricity, Gas and Water." Accessed January 20, 2018.

https://www.city-cost.com/blogs/City-Cost/MAA6M-livi ng_money.

[35] Water UK. 2018. "Household Water and Sewerage Bills for 2017-18." Accessed January 20, 2018. https://www.water.org.uk/news-water-uk/latest-news/hou sehold-water-and-sewerage-bills-2017-18.

[36] World Bank. 2010. Project Paper on a Proposed Additional Financing Credit in the Amount of SDR 42 million to the Socialist Republic of Vietnam for the River Delta Rural Water Supply and Sanitation Project. World Bank. 